\title{
Urban neighbourhoods and intergroup relations: The importance of place identity
}

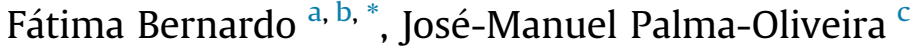 \\ a Departamento de Psicologia, Universidade de Évora, Portugal \\ ${ }^{\mathrm{b}}$ CESUR, CERIS, IST, Universidade de Lisboa, Portugal \\ ${ }^{\mathrm{c}}$ Faculdade de Psicologia, Universidade de Lisboa, Portugal
}

\section{A R T I C L E I N F O}

Article history:

Received 3 July 2015

Received in revised form

15 January 2016

Accepted 21 January 2016

Available online 22 January 2016

\section{Keywords:}

Place identity

Intergroup relations

\begin{abstract}
A B S T R A C T
The aim of this paper is to bring the concept of place identity into the context of intergroup relationships in urban place, using the social identity approach. A field study was conducted in four adjacent neighbourhoods in the city of Lisbon, in order to explore the influence of place identity on the perception of the participants' own neighbourhood and its residents (in-group) and of the other neighbourhoods and their residents (out-groups). The results showed that place identity was highly correlated with neighbourhood satisfaction, relevant out-group differentiation, and favouritism to the in-group and depreciation of the relevant out-group. The results also enabled the identification of three types of possible relationships between the groups: a relevant out-group for comparison, an idealized reference group for approximation, and a devaluated group for avoidance. Moreover, in this study, we extend the predictions of SIA to the comprehension of specific distance estimation distortion patterns.
\end{abstract}

(c) 2016 Elsevier Ltd. All rights reserved.

\section{Introduction}

Since the 1960s, the importance of the spaces where we live for the identity of the subject has been recognized. First, the study by Fried (1963) regarding forced relocation in the city of Boston, and some years later the introduction of the concept of place identity by Proshansky and colleagues (Proshansky, Fabian, \& Kaminoff, 1983), emphasized the idea that self-identity not only was based on individual, interpersonal and social processes but also included physical environments, making place a fundamental component of personal identity.

Introduction of the Place Identity concept, despite the controversy concerning its conceptualization and operationalization (e.g., Dixon \& Durrheim, 2004; Twigger-Ross, Bonaiuto, \& Breakwell, 2003), led to a proliferation of research over the last decades.

\footnotetext{
* Corresponding author. Departamento de Psicologia, Universidade de Évora, Portugal, Colegio Pedro da Fonseca, Rua da Barba Rala, 7000 Évora, Portugal.

E-mail addresses: fatimab@uevora.pt (F. Bernardo),jpalma-oliveira@fp.ul.pt (J.-M. Palma-Oliveira).

1 That idea was not new. In fact, there are references to the importance of place and things for self-identity in authors such as James (1890), Mead (1934) and Erikson (1956). For instance, Erikson (1946) introduced the concept of "spatial identity", and stated that spatial aspects, such as place status, were important factors in the definition of identity.
}

However, the concept of place identity from Proshansky and colleagues' point of view, as well as for most of the authors who have used the concept until now, was centred on an individualistic perspective, thus neglecting the social nature of the relations between individuals, identities and place (Bernardo \& Palma-Oliveira, 2012; Dixon \& Durrheim, 2000). We define, place identity, as a component of personal and social identity, a "process by which, through interaction with places, people describe themselves in terms of belonging to a specific place" (Hernandez, Hidalgo, Salazar-Laplace \& Hess, 2007). Following the tradition of Canter (1977) and Stokols (1981) place is conceptualized as an interchangeable relationship between the physical-spacial and humansocial characteristics of space. In this sense, place identity cannot not be understood without including both components (Proshansky et al., 1983). Thus, place identity can be grasped from its multiple components (spatial-physical and social issues) and the multi-place nature of individual and social place experience (individual and social meanings, feelings and experiences) (Clayton et al., 2015; Manzo \& Devine-Wright, 2013). A third aspect that will be addressed later, is the multi-scale of places (e.g., Bonaiuto \& Alves, 2012; Bonaiuto, Bonnes, \& Continisio, 2004; Hernandez et al., 2007).

With the study presented here, we intended to bring the concept of place identity into the context of intergroup 